\title{
In reply: Assessing interaction between dexmedetomidine and propofol
}

\author{
Ji Young Yoo ${ }^{1} \cdot$ Jong Yeop Kim ${ }^{1}$
}

Received: 2 November 2016 / Accepted: 5 November 2016 / Published online: 14 November 2016

(C) Japanese Society of Anesthesiologists 2016

Keywords Dexmedetomidine $\cdot$ Interaction $\cdot$ Propofol

To the Editor:

We thank Dr. Yang and his colleagues for their comments on our study 'The effect of dexmedetomidine pretreatment on the median effective bolus dose of propofol for facilitating laryngeal mask airway insertion' [1]. We agree that a different median effective dose of propofol for LMA insertion would have been obtained if we waited for the peak effect of dexmedetomidine (15 min), because onset time of a drug is critical in evaluating the effect of an adjuvant drug during anesthesia induction.

In our study, 10 min after dexmedetomidine infusion, following propofol injection over $30 \mathrm{~s}$, LMA insertion was performed $90 \mathrm{~s}$ later. Basically, an initial loading dose of dexmedetomidine should be injected over $10 \mathrm{~min}$, and its onset of action is less than $5 \mathrm{~min}$ and the peak effect occur within $15 \mathrm{~min}$ [2]. In the many studies in regard to anesthetic requirement and hemodynamic response during anesthetic induction, dexmedetomidine was injected over $10 \min [3,4]$.

We can use dexmedetomidine not only for the smooth anesthesia induction but also for the reduction of intraoperative anesthetic requirement, smooth emergence, and postoperative analgesic effect. In busy clinical settings, especially

This reply refers to the article available at doi:10.1007/s00540016-2258-2.

\footnotetext{
Jong Yeop Kim

kjyeop@ajou.ac.kr

1 Department of Anesthesiology and Pain Medicine,, Ajou

University School of Medicine,, San 5, Wonchon-dong,

Yeongtong-gu, Suwon 443-721, Korea
}

in the short-time anesthesia using the LMA or other supraglottic airway, the rapid induction technique has practical advantage. To fit conditions similar to clinical practice, we inserted the LMA $90 \mathrm{~s}$ after propofol administration instead of waiting $15 \mathrm{~min}$ of the peak onset time in our study.

\section{Compliance with ethical standards}

Conflict of interest None.

\section{References}

1. Yoo JY, Kwak HJ, Kim YB, Park CK, Lee SY, Kim JY. The effect of dexmedetomidine pretreatment on the median effective bolus dose of propofol for facilitating laryngeal mask airway insertion. J Anesth. 2016; doi:10.1007/s00540-016-2245-7.

2. Kaur M, Singh PM. Current role of dexmedetomidine in clinical anesthesia and intensive care. Anesth Essays Res. 2011;5:128-33.

3. Chandra A, Ranjan R, Kumar J, Vohra A, Thakur VK. The effects of intravenous dexmedetomidine premedication on intraocular pressure and pressor response to laryngoscopy and intubation. $\mathbf{J}$ Anaesthesiol Clin Pharmacol. 2016;32:198-202.

4. Shin HW, Yoo HN, Kim DH, Lee H, Shin HJ, Lee HW. Preanesthetic dexmedetomidine $1 \mu \mathrm{g} / \mathrm{kg}$ single infusion is a simple, easy, and economic adjuvant for general anesthesia. Korean J Anesthesiol. 2013;65:114-20. 